\title{
BMJ Open Impact of smoking on health system costs among cancer patients in a retrospective cohort study in Ontario, Canada
}

\author{
Wanrudee Isaranuwatchai, ${ }^{1,2}$ Claire de Oliveira, ${ }^{2,3}$ Nicole Mittmann, ${ }^{2,4}$ \\ William K (Bill) Evans, ${ }^{5}$ Alice Peter, ${ }^{5}$ Rebecca Truscott, ${ }^{5}$ Kelvin KW Chan ${ }^{2,4,6}$
}

To cite: Isaranuwatchai W, de Oliveira C, Mittmann N, et al. Impact of smoking on health system costs among cancer patients in a retrospective cohort study in Ontario, Canada. BMJ Open 2019;9:e026022. doi:10.1136/ bmjopen-2018-026022

\section{- Prepublication history and} additional material for this paper are available online. To view these files, please visit the journal online (http://dx.doi. org/10.1136/bmjopen-2018026022).

Received 22 August 2018 Revised 2 April 2019 Accepted 18 April 2019
Check for updates

(C) Author(s) (or their employer(s)) 2019. Re-use permitted under CC BY-NC. No commercial re-use. See rights and permissions. Published by BMJ.

For numbered affiliations see end of article.

Correspondence to Dr Wanrudee Isaranuwatchai; IsaranuwatcW@smh.ca

\section{ABSTRACT}

Objective Smoking is the main modifiable cancer risk factor. The objective of this study was to examine the impact of smoking on health system costs among newly diagnosed adult patients with cancer. Specifically, costs of patients with cancer who were current smokers were compared with those of non-smokers from a publicly funded health system perspective.

Methods This population-based cohort study of patients with cancer used administrative databases to identify smokers and non-smokers (1 April 2014-31 March 2016) and their healthcare costs in the 12-24 months following a cancer diagnosis. The health services included were hospitalisations, emergency room visits, drugs, home care services and physician services (from the time of diagnosis onwards). The difference in cost (ie, incremental cost) between patients with cancer who were smokers and those who were non-smokers was estimated using a generalised linear model (with log link and gamma distribution), and adjusted for age, sex, neighbourhood income, rurality, cancer site, cancer stage, geographical region and comorbidities.

Results This study identified 3606 smokers and 14911 non-smokers. Smokers were significantly younger (61 vs 65 years), more likely to be male (53\%), lived in poorer neighbourhoods, had more advanced cancer stage,and were more likely to die within 1 year of diagnosis, compared with non-smokers. The regression model revealed that, on average, smokers had significantly higher monthly healthcare costs (\$5091) than non-smokers (\$4847), $p<0.05$.

Conclusions Smoking status has a significant impact on healthcare costs among patients with cancer. On average, smokers incurred higher healthcare costs than non-smokers. These findings provide a further rationale for efforts to introduce evidence-based smoking cessation programmes as a standard of care for patients with cancer as they have the potential not only to improve patients' outcomes but also to reduce the economic burden of smoking on the healthcare system.

\section{INTRODUCTION}

Cancer care is a substantial component of healthcare expenditures of developed countries. ${ }^{1-3}$ In Canada, the economic burden
Strengths and limitations of this study

- Findings from this study represent one piece of evidence in support of the integration of smoking cessation programmes into cancer care treatment plans as a standard of practice.

- This study adds to the literature by providing upto-date and precise healthcare cost estimates of smoking using existing administrative person-level costing approaches.

- A limitation of this study is that it excludes a subset of relevant variables that may have had an influence on health outcomes and cost due to the nature of the study design (eg, type of tumour, amount and duration of smoking).

- This study focused on the cost incurred to the public healthcare payer and, therefore, indirect costs were not considered but could be explored in future research.

- The findings from this study should motivate policy makers to design, implement and fund smoking cessation programmes, which have the potential not only to improve patients' treatment outcomes but also to reduce the economic burden of smoking on the healthcare system.

of cancer was estimated to be $\$ 7.5$ billion in 2012. ${ }^{4}$ It is well recognised that smoking is the main modifiable risk factor for cancer, ${ }^{5}$ and it is estimated that it contributes to approximately $30 \%$ of all cancer deaths. ${ }^{6} 7$ Smoking can also harm directly or indirectly almost every organ of the body and is responsible for a number of other chronic diseases that contribute to higher healthcare costs. ${ }^{5-11}$ Quitting smoking after a diagnosis of cancer has been associated with improved general health, better quality of life, reduced toxicity, greater response to treatment (such as radiation therapy) and decreased risk of disease recurrence and second primary cancers. ${ }^{12-18}$ Nevertheless, patients with cancer are just as likely to smoke as the general public, with the 
smoking rate being approximately 20\%. ${ }^{19}$ Furthermore, smoking cessation programmes are rare in oncology settings. $^{12} 1320$

Although the impact of smoking on healthcare costs has been examined in the general population, there is very little information on the impact of smoking on the cost of cancer care in patients who are smokers compared with those who are not.

The study objective was to compare the health system costs of patients with cancer who were current smokers with those of non-smokers between 2014 and 2016, from the perspective of a public healthcare payer, using administrative databases in Ontario, Canada. We hypothesised that smoking would be associated with higher overall health system costs as a result of the need to manage more frequent and severe toxicities of treatment, more frequent disease recurrence and more non-cancer-related morbidities. Understanding the cost burden of smokers with cancer may help drive policy change by providing an economic argument for investing in cessation resources and programmes for patients with cancer who smoke.

\section{MATERIALS AND METHODS}

This study was a secondary data analysis using existing administrative databases at Cancer Care Ontario (CCO) and the Institute for Clinical Evaluative Sciences (ICES), both located in Toronto, Ontario, Canada.

\section{Study population and setting}

The study population consisted of newly diagnosed adult patients with cancer, aged $\geq 18$ years, who received ambulatory care from one of the 14 Regional Cancer Centres (RCCs) in Ontario, Canada, between 1 April 2014 and 31 March 2015. The Ontario Cancer Registry (OCR) was used to identify our study population. We excluded patients with (1) an invalid health card (ie, who were not eligible for public healthcare insurance); (2) an invalid death date (ie, where death date was on or before the date of diagnosis); (3) missing data on smoking status; (4) a cancer stage of zero; (5) missing data on neighbourhood-level income, geographical location or rurality of residence; (6) lost healthcare coverage during the follow-up time; or (7) multiple cancers. Each patient was followed until death or the end of the observation period (31 March 2016), whichever came first. Online S1 appendix provides a flow diagram of the number of patients excluded from the analysis.

\section{Study population subgroups (smokers and non-smokers)}

The study population of patients with cancer was divided into those who were identified as smokers and non-smokers. Patients with cancer who were either currently smoking at the time of diagnosis or who had smoked in the previous 6 months of their first ambulatory care visit were identified as smokers, whereas all others were identified as non-smokers. Information on smoking status was obtained from the CCO Smoking Cessation Dataset
(CCOSCD), which is part of the Activity Level Reporting (ALR) database housed at CCO. The CCOSCD collects information on the self-reported smoking status of newly diagnosed ambulatory patients with cancer, whether the current smoker has been advised to quit, and whether the patient has been referred for smoking cessation counselling and/or pharmacotherapy. ${ }^{21}$ Each RCC submits the data on these metrics on a monthly basis to CCO as part of CCO's Smoking Cessation Programme. Online S2 appendix describes the data elements in the data set and their definitions.

\section{Data sources and variables}

A number of databases were used to obtain healthcare utilisation data: the ALR database, the New Drug Funding Programme database, the Ontario Drug Benefit claims database, the Discharge Abstract Database obtained from the Canadian Institute for Health Information (CIHI), the National Ambulatory Care Reporting System obtained from CIHI, the Ontario Health Insurance Programme claims database, the Home Care Database, the Continuing Care Reporting System and the National Rehabilitation Reporting System. Table 1 provides a brief description of each database.

\section{Healthcare costs}

The outcome of interest for the study was total and disaggregated healthcare costs from the perspective of the Ontario Ministry of Health and Long-Term Care from the time of diagnosis. Patients in Ontario receive publicly funded healthcare, which covers costs for health services (eg, hospitalisation) including the costs of most drugs for patients over the age of 65 years or who are on social assistance. Healthcare costs included costs associated with hospitalisations, same-day surgeries, emergency room (ER) visits, outpatient prescription drugs, rehabilitation, complex continuing care, home care services, physician services, and laboratory and diagnostic tests. Cost estimates were derived using an existing costing algorithm at ICES. For example, hospitalisations and ER visit costs were estimated by multiplying a resource intensity weight (measure of utilisation) with an average cost per hospital stay or ER visit (unit cost). ${ }^{22}$ Physician visit costs were obtained from the Ontario Schedule of Benefits for Physician Services. ${ }^{23}$ Additional details on the methods to estimate cost can be found elsewhere. ${ }^{4224}$ Costs were adjusted to 2016 Canadian dollars (\$C) using the health component of the Consumer Price Index in healthcare category $\left(\$ \mathrm{C} 1=\right.$ approximately US\$0.78). ${ }^{25}$

\section{Other variables}

Due to potential differences between smokers and non-smokers, we controlled for patient characteristics by adjusting for a number of variables such as age at diagnosis, sex, cancer site, cancer stage (where available), geographical location of residence (ie, rurality and Local Health Integration Network (LHIN)), neighbourhood income quintile and comorbidity (measured 


\section{Table 1 Administrative databases used in the analysis

\begin{tabular}{ll} 
Database & Description \\
\hline OCR & $\begin{array}{l}\text { The Ontario Cancer Registry is the largest population- } \\
\text { based cancer registry in Canada. The OCR contains } \\
\text { over } 300 \text { fields, including primary site of cancer, } \\
\text { county of residence at diagnosis and health insurance } \\
\text { number. }\end{array}$ \\
ALR & $\begin{array}{l}\text { The Ontario Activity Level Reporting provides a set of } \\
\text { data elements from selected Ontario Cancer Centres } \\
\text { that cannot be obtained from other providers. This } \\
\text { information is used to support management decision- } \\
\text { making process. }\end{array}$
\end{tabular}

\begin{tabular}{|c|c|}
\hline NDFP & $\begin{array}{l}\text { The New Drug Funding Programme data are used } \\
\text { for reimbursement decisions and to support cancer } \\
\text { system planning for systemic therapy. To be eligible } \\
\text { for reimbursement through the NDFP, hospitals must } \\
\text { submit eligibility/enrolment data and treatment data } \\
\text { in compliance with monthly billing deadlines. For } \\
\text { treatment reimbursement, each patient must be } \\
\text { enrolled in the NDFP by providing eligibility/enrolment } \\
\text { data that include patient-specific demographic } \\
\text { information and answers to a series of medical } \\
\text { questions. }\end{array}$ \\
\hline ODB & $\begin{array}{l}\text { The Ontario Drug Benefit Formulary lists prescription } \\
\text { drugs that are covered for patients over } 65 \text { years and } \\
\text { selected other groups (eg, those that require income } \\
\text { supports). }\end{array}$ \\
\hline CIHI DAD & $\begin{array}{l}\text { Hospitalisation and comorbidity data are in the } \\
\text { Discharge Abstract Database from the Canadian } \\
\text { Institute for Health Information. }\end{array}$ \\
\hline $\begin{array}{l}\text { CIHI } \\
\text { NACRS }\end{array}$ & $\begin{array}{l}\text { Emergency room visits and same-day surgery data } \\
\text { were obtained from the National Ambulatory Care } \\
\text { Reporting System. }\end{array}$ \\
\hline OHIP & $\begin{array}{l}\text { Ontario Health Insurance Programme reports } \\
\text { outpatient physician visits based on fee-for-service } \\
\text { claims. }\end{array}$ \\
\hline HCD & $\begin{array}{l}\text { Home Care Database captures all home care services } \\
\text { in Ontario. }\end{array}$ \\
\hline CCRS & $\begin{array}{l}\text { The Continuing Care Reporting System reports } \\
\text { utilisation of continuing care. }\end{array}$ \\
\hline NRS & $\begin{array}{l}\text { National Rehabilitation Reporting System captures } \\
\text { rehabilitation utilisation. }\end{array}$ \\
\hline
\end{tabular}

by the Adjusted Clinical Groups or ACG), all of which were obtained from the previously mentioned databases. In Ontario, publicly funded healthcare services are administered on a regional basis by the LHINs, which serve as the regional health authority. Each of the 14 LHINs is responsible for a distinct geographical location. ${ }^{26}$ The ACG system is a patient case-mix adjustment system used to measure health status by grouping diagnoses into clinical groups. The goal of this system is to assign each patient a single value, which represents the patient's comorbidity through his/her expected or actual use of health services, where a higher number refers to a greater number of comorbidities (0-4, 5-6, $7-9$ and $10+) .{ }^{27}$ In this study, this value was assigned at the time of the cancer diagnosis. Cancer sites or groupings were reported on as follows: bladder; bronchus and lung; breast; colorectal; corpus uteri; head and neck; prostate; melanoma; and 'other'. Other included cancers of the anus and anal canal, brain, oesophagus, haematopoietic system, liver, ovary, pancreas, renal, stomach, testis and thyroid. The four most common types of cancer were lung, breast, colorectal and prostate cancer. The extent of cancer was reported in one of three groups: stage 1-2; stage 3-4; and unknown stage. Cancer stage data in Ontario were available predominantly for the four most common types of cancer (eg, lung, breast, prostate and colorectal); therefore, it was necessary to create a separate category for unknown cancer stage.

\section{ANALYSIS}

The raw costs for non-smokers and smokers were reported descriptively. To adjust for different follow-up times, as some patients (particularly smokers) have a greater chance of dying than non-smokers, we estimated personmonth costs. $^{28}$

The output of the economic analysis was the incremental cost (reported in $2016 \mathrm{CAD}$ ) between patients with cancer who smoked and those who did not. We analysed our dependent variable (monthly healthcare costs) using regression models to estimate the difference in expected healthcare cost between the two groups using recycled predictive methods, ${ }^{28-30}$ as described in the following equation:

Cost $_{\mathrm{i}}=\beta_{0}+\beta_{1}(\text { smoking status })_{\mathrm{i}}+\beta_{2}(\text { age })_{\mathrm{i}}+\beta_{3}(\text { sex })_{\mathrm{i}}+\beta_{4}($ in -

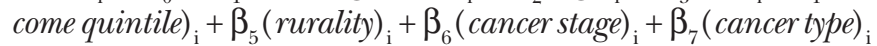
$+\beta_{8}(L H I N)_{\mathrm{i}}+\varepsilon_{\mathrm{i}}$, where cost $\mathrm{i}_{\mathrm{i}}$ represents a monthly cost of patient $I ; \beta_{\mathrm{x}}$ refers to a coefficient estimate of each variable, $X$, such as smoking status, age and sex; and $\varepsilon$ represents the error term. The smoking status variable was the primary independent variable, and the regression model was adjusted for potential confounding variables, such as age, sex, income, rurality, cancer stage, cancer site, geographical region (LHIN) and comorbidity. To accommodate for the skewness of cost data, a generalised linear model with log link and gamma family was used to estimate the incremental cost between smokers and non-smokers. ${ }^{2831}$ We also conducted a modified Park test to ensure that our selected model was the best fit. ${ }^{28} 31$ Collinearity was also explored using a variance inflation factor, and we found no evidence of collinearity. Online S3 appendix reports a completed Strengthening the Reporting of Observational Studies in Epidemiology statement, a checklist of items that should be included in reports of cohort studies.

\section{Patient and public involvement}

There was no involvement of patients during the study period but there are knowledge translation activities with various knowledge users.

\section{RESULTS}

There were 3606 smokers and 14911 non-smokers in our study cohort (see table 2). Patients with cancer who smoked were significantly younger (61 vs 65 years), more 
Table 2 Demographic characteristics of study population between smokers and non-smokers

\begin{tabular}{|lcc|}
\hline Variable $^{*}$ & Non-smokers & \multicolumn{1}{l}{ Smokers } \\
\hline $\mathrm{n}$ & 14911 & 3606 \\
\hline Mean age in years (SD) & $65.1(13.6)$ & $60.6(12.1)$ \\
\hline Male & $6681(44.8 \%)$ & $1907(52.9 \%)$ \\
\hline Age groups in years, $\mathrm{n}(\%)$ & & \\
\hline $18-44$ & $1116(7.5 \%)$ & $310(8.6 \%)$ \\
\hline $45-54$ & $1973(13.2 \%)$ & $661(18.3 \%)$ \\
\hline $55-64$ & $3443(23.1 \%)$ & $1217(33.7 \%)$ \\
\hline $65-74$ & $4525(30.3 \%)$ & $1035(28.7 \%)$ \\
\hline $75+$ & $3854(25.8 \%)$ & $383(10.6 \%)$ \\
\hline Income quintile, $\mathrm{n}(\%)$ & & \\
\hline 1 (lowest) & $2387(16.0 \%)$ & $887(24.5 \%)$ \\
\hline 2 & $2597(17.4 \%)$ & $818(22.7 \%)$ \\
\hline 3 & $3065(20.6 \%)$ & $691(19.2 \%)$ \\
\hline 4 & $3351(22.5 \%)$ & $649(18.0 \%)$ \\
\hline 5 (highest) & $3511(23.5 \%)$ & $561(15.6 \%)$ \\
\hline Living in rural areas, $\mathrm{n}(\%)$ & $2267(15.2 \%)$ & $662(18.4 \%)$ \\
\hline Death within 1 year, $\mathrm{n}(\%)$ & $2211(14.8 \%)$ & $850(23.6 \%)$ \\
\hline
\end{tabular}

Mean time from diagnosis to 255.2 days (163.3) 236.8 days (159.6) death (SD)

\begin{tabular}{|lcr|}
\hline Comorbidity (ACG), n (\%) & & \\
\hline $0-4$ & $3589(24.1 \%)$ & $1092(30.3 \%)$ \\
\hline $5-6$ & $3295(22.1 \%)$ & $838(23.2 \%)$ \\
\hline $7-9$ & $4533(30.4 \%)$ & $985(27.3 \%)$ \\
\hline $10+$ & $3494(23.4 \%)$ & $691(19.2 \%)$ \\
\hline Cancer stage, n (\%) & & \\
\hline $1-2$ & $6378(42.8 \%)$ & $1289(35.7 \%)$ \\
\hline $3-4$ & $3958(26.5 \%)$ & $1392(38.6 \%)$ \\
\hline Unknown & $4575(30.7 \%)$ & $925(25.7 \%)$ \\
\hline Cancer types, n (\%) & & \\
\hline Lung & $1673(11.2 \%)$ & $1017(28.2 \%)$ \\
\hline Breast & $3088(20.7 \%)$ & $497(13.8 \%)$ \\
\hline Head and neck & $614(4.1 \%)$ & $292(8.1 \%)$ \\
\hline Prostate & $1694(11.4 \%)$ & $290(8.0 \%)$ \\
\hline Colorectal & $1460(9.8 \%)$ & $268(7.4 \%)$ \\
\hline Melanoma & $563(3.8 \%)$ & $81(2.2 \%)$ \\
\hline Corpus uteri & $701(4.7 \%)$ & $64(1.8 \%)$ \\
\hline Bladder & $196(1.3 \%)$ & $43(1.2 \%)$ \\
\hline Other & $4922(33.0 \%)$ & $1054(29.3 \%)$ \\
\hline
\end{tabular}

${ }^{*}$ The two groups were significantly different across all variables $(p<0.05)$.

ACG, Adjusted Clinical Groups; n, sample size.

likely to be male ( $53 \%$ vs $45 \%$ ), live in lower income neighbourhoods (25\% of smokers compared with $16 \%$ of non-smokers were in the lowest income quintile) and more likely to live in rural areas (18\% vs $15 \%)$ compared with patients with cancer who were non-smokers. Cancer stage data were available for approximately $70 \%$ of patients over the study period. Of those with available cancer stage data, smokers were more likely to have advanced cancer stages than non-smokers. Almost $40 \%$ of smokers were in stage 3-4 compared with approximately $27 \%$ of non-smokers. Roughly $25 \%$ of smokers died within 1 year of diagnosis compared with $15 \%$ of non-smokers who died over the same follow-up period. Approximately $30 \%$ of smokers were in the lowest comorbidity level (0-4) compared with $24 \%$ of non-smokers. Only $19 \%$ of smokers were in the highest comorbidity level $(10+)$ compared with $23 \%$ of non-smokers. Among all cancer types studied, lung cancer was the most common type of cancer among smokers followed by breast cancer. For non-smokers, the most common cancer type was breast cancer followed by prostate cancer and lung cancer (table 2); all three were identified as common types of cancer.

Online S4 appendix reports the unadjusted monthly healthcare costs between the study groups. Generally, smokers incurred higher healthcare costs than non-smokers for hospitalisations, physician services, ER visits, home care services and complex continuing care. Focusing on specific types of healthcare costs, smokers had approximately $30 \%$ higher hospitalisation costs, $43 \%$ higher ER visit costs, 23\% higher physician visit costs and 30\% higher home care costs than non-smokers. Overall, total monthly healthcare costs were higher among smokers $(\$ 5649 \pm \$ 7169)$ than non-smokers (\$4704 $\pm \$ 6737)$.

From the adjusted regression model (controlling for age, sex, income, rurality, stage, disease site, geographical region and comorbidity), on average, smokers had significantly higher monthly healthcare costs (\$5091) than non-smokers (\$4847). Smokers incurred \$244 $( \pm 113 ; 95 \%$ CI $\$ 242, \$ 245$ and IQR $\$ 145, \$ 328$ ) more in healthcare cost per month, or $\$ 2928$ more per year than non-smokers, $\mathrm{p}=0.0047$.

\section{DISCUSSION}

Understanding the impact of smoking on the healthcare costs of patients with cancer may strengthen the rationale for decision makers to further invest in smoking cessation programmes. It is generally understood that smoking can lead to worse clinical outcomes, but there is a paucity of literature on the impact of smoking on healthcare costs among patients with cancer. The findings from this analysis are aligned with the limited available literature. Specifically, we found that patients with cancer who were smokers were younger and more commonly males compared with patients with cancer who were not smokers, which is in line with the literature. ${ }^{10} 32$ Additionally, smokers had, on average, almost $20 \%$ higher total monthly healthcare costs than non-smokers. When focusing mainly on hospitalisations, the incremental cost due to smoking was approximately $30 \%$ higher than non-smokers, in contrast to an increase of up to $50 \%$ in incremental hospitalisation costs among smokers reported in the literature. ${ }^{93}$ Our findings suggest that patients with cancer who are smokers are responsible for a greater economic burden than non-smokers. 
Evidence on the importance of smoking cessation for patients with cancer has strengthened in recent years. Several cancer care institutions in the USA have emerged as leaders in this field by incorporating smoking cessation programmes into practice. ${ }^{34}$ Ontario is the first jurisdiction in North America to implement a systematic smoking cessation programme in all of its RCCs. Under the leadership of $\mathrm{CCO}$, the provincial agency responsible for improving the quality of cancer services in Ontario, a smoking cessation programme provides support for new ambulatory patients with cancer by screening patients for tobacco use, advising on the benefits of quitting and offering referrals to smoking cessation resources. Understanding the impact of smoking on the healthcare costs incurred by patients with cancer may further strengthen the rationale for the programme and encourage policy makers (eg, public healthcare payer) to invest in smoking cessation programmes. The findings from this study may also be beneficial to other cancer agencies and not-forprofit organisations (eg, American Cancer Society, Worldwide Cancer Research and Canadian Partnership Against Cancer) engaged in developing smoking cessation policies and implementing smoking cessation programmes. In addition, this study may help to inform the general public about the burden of smoking among patients with cancer and motivate hospital and health system administrators about the incremental economic impact of failing to help patients with cancer quit smoking. The findings from this study represent a further piece of evidence in support of the integration of smoking cessation programmes into cancer care treatment plans (in settings similar to the study setting) and will hopefully stimulate further research into the optimal implementation of smoking cessation programmes in order to improve cancer care outcomes and reduce morbidity, mortality and cost.

This study has strengths and limitations, which should be highlighted. The medical literature has called for more up-to-date and precise healthcare cost estimates of smoking. ${ }^{95}$ Existing Canadian literature has used cost estimates for smokers from the 1990s and/or employed high-level costing approaches, instead of using patient-level cost estimates. These prior estimates might not accurately reflect the true healthcare cost difference between smokers and non-smokers. ${ }^{935-37}$ This study represents a first step in systematically collecting these data and linking them to data on system-level resources. Furthermore, using existing data from administration databases, we were able to conduct the analysis with adjustment of potential confounders to increase the validity of the findings.

In terms of limitations, data on smoking status were limited to one assessment during the initial consultation period (28 days) for new ambulatory patients with cancer. Therefore, it is possible that patients may have changed their smoking status after their cancer diagnosis but data on change in smoking status were not captured. Our analysis followed the intent-to-treat principle and was applied to both study groups (ie, smokers at the time of diagnosis or who had quit in the last 6 months remained smokers throughout the analysis and vice versa). If some 'smokers' quit smoking, their medical outcomes or tolerance to treatment may have been better than that of persistent smokers (presumably with less resource utilisation and less cost). Consequently, this analysis may have provided a lower bound of the incremental cost. Individuals who had quit prior to 6 months would likely still have more health complications and resource utilisation than life-long non-smokers. Classification of these patients as non-smokers may again lead to the possibility of an underestimation of the difference in cost between smokers and non-smokers. The data available on smoking status limited our ability to analyse former smokers and recent quitters as separate groups.

Our analysis was also limited by the available follow-up data. As the follow-up period was relatively short, it is possible that significant differences might be observed with a longer period of follow-up. It is also possible that, given the nature of the study design, relevant variables were not collected. For example, cancer stage data were available for the common types of cancer (ie, lung, breast, colorectal and prostate cancer), but not for some other tumour types, such as head and neck cancer. In addition to the common cancer types, our study included other tumour types (eg, brain, liver) but their smaller numbers did not allow us to examine them separately. This could be a future area of research. Patients with multiple cancers were excluded from the study to distinguish the impact of smoking on a single tumour type. In addition, there were no data available on the amount or duration of smoking, which would likely have an influence on health outcomes and cost. Smoking has been shown to increase both direct and indirect costs. ${ }^{9637}$ However, because our study used administrative data, indirect costs were not explored. Future clinical trials could consider prospectively documenting the specific clinical and financial benefits of smoking cessation as part of clinical care to evaluate the smoking cessation programmes. Finally, the cost to implement a smoking cessation programme was not included in this analysis and may cancel out some of the economic benefits of helping smokers to stop smoking.

In conclusion, the smoking status of patient with cancer has a significant impact on health system costs. On average, smokers incurred higher healthcare costs than non-smokers. These findings provide an additional reason for the introduction of evidence-based smoking cessation programmes for patients with cancer. The findings from this study should motivate policy makers to fund, design and implement smoking cessation programmes, which have the potential not only to improve patients' treatment outcomes but also to reduce the economic burden of smoking on the healthcare system.

\section{Author affiliations}

${ }^{1}$ Centre for exceLlence in Economic Analysis Research (CLEAR), St. Michael's Hospital, Toronto, Ontario, Canada

${ }^{2}$ Institute of Health Policy, Management and Evaluation, University of Toronto, Toronto, Ontario, Canada 
${ }^{3}$ Institute for Mental Health Policy Research, Centre for Addiction and Mental Health, Toronto, Ontario, Canada

${ }^{4}$ Sunnybrook Health Sciences Centre, Sunnybrook Hospital, Toronto, Ontario,

Canada

${ }^{5}$ Prevention and Cancer Control, Cancer Care Ontario, Toronto, Ontario, Canada ${ }^{6}$ Clinical Programs and Quality Initiatives, Cancer Care Ontario, Toronto, Ontario, Canada

Acknowledgements We would like to acknowledge the assistance of Refik Saskin and Lisa Ellison from the Institute for Clinical Evaluative Sciences (ICES), and Stephanie Young, Mohammad Hoque, Elisa Candido, Julie Klein-Geltink, Brooke Filsinger, the Cancer Care Ontario (CCO) Research Office, and the Data Disclosure Committee from CCO including Ashna Jinah and Dr Deena from St. Michael's Hospital for preparation of submission. This study made use of de-identified data from the ICES Data Repository, which is managed by the ICES with support from its funders and partners: Canada's Strategy for Patient-Oriented Research (SPOR), the Ontario SPOR Support Unit, the Canadian Institutes of Health Research and the Government of Ontario. The opinions, results and conclusions reported are those of the authors. No endorsement by ICES or any of its funders or partners is intended or should be inferred. Parts of this material are based on data and/or information compiled and provided by Canadian Institute for Health Information (CIHI). However the analyses, conclusions, opinions and statements expressed in the material are those of the author(s) and not necessarily those of $\mathrm{ClHI}$. Parts of this material are based on data and information provided by CCO. The opinions, results, view and conclusions reported in this paper are those of the authors only.

Contributors All authors made important contributions to this work. WI, CdO, NM, WKBE, AP, RT and KC contributed to this study's conception and design. WI, NM $\mathrm{AP}$ and RT were responsible for data collection and assembly. All authors (Wl, CdO, $\mathrm{NM}, \mathrm{WKBE}, \mathrm{AP}, \mathrm{RT}, \mathrm{KC}$ ) were involved in data analysis and interpretation. WI, Cd0, NM and WKBE drafted the paper, and all authors critically reviewed and suggested amendments prior to submission. The corresponding author attests that all listed authors meet authorship criteria and that others not meeting the criteria have been omitted.

Funding This work was funded by the Canadian Centre for Applied Research in Cancer Control (ARCC). ARCC receives core funding from the Canadian Cancer Society Research Institute (Grant No: 2015-703549).

Competing interests None declared.

Patient consent for publication Not required.

Ethics approval Research ethics approval was obtained from St. Michael's Hospital, Toronto, Ontario, Canada.

Provenance and peer review Not commissioned; externally peer reviewed.

Data sharing statement This study made use of de-identified data from the Institute for Clinical Evaluative Sciences and Cancer Care Ontario who have the right and control over the data used.

Open access This is an open access article distributed in accordance with the Creative Commons Attribution Non Commercial (CC BY-NC 4.0) license, which permits others to distribute, remix, adapt, build upon this work non-commercially, and license their derivative works on different terms, provided the original work is properly cited, appropriate credit is given, any changes made indicated, and the use is non-commercial. See: http://creativecommons.org/licenses/by-nc/4.0/.

\section{REFERENCES}

1. Kesselheim AS, Avorn J, Sarpatwari A. The High cost of prescription drugs in the United States: origins and prospects for reform. JAMA 2016;316:858-71.

2. Vogler S, Vitry A, Babar ZU. Cancer drugs in 16 European countries, Australia, and New Zealand: a cross-country price comparison study. Lancet Oncol 2016;17:39-47.

3. Canadian Cancer Society. Nearly 1 in 2 Canadians expected to get cancer: report. 2017 http://www.cancer.ca/en/about-us/for-media/ media-releases/national/2017/canadian-cancer-statistics/?region= bc.

4. de Oliveira C, Weir S, Rangrej J, et al. The economic burden of cancer care in Canada: a population-based cost study. CMAJ Open 2018;6:E1-E10.

5. Cancer Care Ontario. Cancer Risk Factors in Ontario: Tobacco. 2014

6. American Cancer Society. Tobacco-related cancers fact sheet 2014. 2014 http://www.cancer.org/cancer/cancercauses/tobaccocancer/ tobacco-related-cancer-fact-sheet.
7. Anand P, Kunnumakkara AB, Kunnumakara AB, et al. Cancer is a preventable disease that requires major lifestyle changes. Pharm Res 2008;25:2097-116.

8. Zimovetz EA, Wilson K, Samuel M, et al. A review of costeffectiveness of varenicline and comparison of cost-effectiveness of treatments for major smoking-related morbidities. J Eval Clin Pract 2011;17:288-97.

9. Sari AA, Rezaei S, Arab M, et al. Effects of Smoking on Cost of Hospitalization and Length of Stay among Patients with Lung Cancer in Iran: a Hospital-Based Study. Asian Pac J Cancer Prev 2016;17:4421-6.

10. Sherratt FC, Field JK, Marcus MW. Association between smoking and health outcomes in an economically deprived population: the Liverpool Lung Project. J Epidemiol Community Health 2017;71:806-10.

11. U.S. Department of Health and Human Services. The Health Consequences of Smoking: 50 Year of Progress. A Report of the Surgeon General. Atlanta, GA: U.S. Department of Health and Human Services, Centers for Disease Control and Prevention, National Center for Chronic Disease Prevention and Health Promotion, Office on Smoking and Health, 2014.

12. Toll BA, Brandon TH, Gritz ER, et al. Assessing tobacco use by cancer patients and facilitating cessation: an American Association for Cancer Research policy statement. Clin Cancer Res 2013;19:1941-8

13. Nayan S, Gupta MK, Strychowsky JE, et al. Smoking cessation interventions and cessation rates in the oncology population: an updated systematic review and meta-analysis. Otolaryngol Head Neck Surg 2013;149:200-11.

14. Cancer Care Ontario. Cancer Fact: Reported tobacco screening increases among new cancer patients. 2017 www.cancercareontario. ca/cancerfacts.

15. Dobson Amato KA, Hyland A, Reed R, et al. Tobacco Cessation May Improve Lung Cancer Patient Survival. J Thorac Oncol 2015;10:1014-9.

16. Gritz ER, Toll BA, Warren GW. Tobacco use in the oncology setting: advancing clinical practice and research. Cancer Epidemiol Biomarkers Prev 2014;23:3-9.

17. Warren GW, Marshall JR, Cummings KM, et al. Automated tobacco assessment and cessation support for cancer patients. Cancer 2014:120:562-9.

18. Warren GW, Sobus S, Gritz ER. The biological and clinical effects of smoking by patients with cancer and strategies to implement evidence-based tobacco cessation support. Lancet Oncol 2014;15:e568-80.

19. Statistics Canada. Current smoking trends. 2015 https://www. statcan.gc.ca/pub/82-624-x/2012001/article/11676-eng.htm.

20. Tota JE, Ramanakumar AV, Franco EL. Lung cancer screening: review and performance comparison under different risk scenarios. Lung 2014;192:55-63.

21. Cancer Care Ontario. Cancer Care Ontario's Data Book - 2016-2017. 2016 https://cancercare.on.ca/ext/databook/db1516/.

22. Guidelines on person-level costing using administrative databases in Ontario. 2013 http://www.hsprn.ca/uploads/files/Guidelines_on PersonLevel_Costing_May_2013.pdf.

23. Ontario Ministry of Health and Long-Term Care. Schedule of Benefits: Physician Services under the Health Insurance Act. 2015 http://www.health.gov.on.ca/en/pro/programs/ohip/sob/physserv/ sob master20151221.pdf.

24. Thein $\mathrm{HH}$, Isaranuwatchai $\mathrm{W}$, Campitelli MA, et al. Health care costs associated with hepatocellular carcinoma: a population-based study. Hepatology 2013;58:1375-84.

25. Statistics Canada. Consumer Price Index (CPI). 2017 http://www5. statcan.gc.ca/cansim/a26?lang=eng\&retrLang=eng\&id=3260020\& paSer $=\&$ pattern $=\&$ stByVal=1\&p1=1\&p2=37\&tabMode $=$ dataTable $\&$ csid $=$.

26. Ontario Ministry of Health and Long-Term Care. Ontario's LHINs. 2017 http://www.lhins.on.ca/.

27. University of Manitoba. Concept: Adjusted Clinical Groups(R) (ACG(R) - Overview. 2015 http://mchp-appserv.cpe.umanitoba.ca/ viewConcept.php?printer $=Y \&$ conceptID=1304.

28. Glick HA, Doshi JA, Sonnad SS, et al. Economic evaluation in clinica trials: OUP Oxford. 2014.

29. Brown ML, Riley GF, Potosky AL, et al. Obtaining long-term disease specific costs of care: application to Medicare enrollees diagnosed with colorectal cancer. Med Care 1999;37:1249-59.

30. Taplin SH, Barlow W, Urban N, et al. Stage, age, comorbidity, and direct costs of colon, prostate, and breast cancer care. J Natl Cancer Inst 1995;87:417-26.

31. Barber J, Thompson S. Multiple regression of cost data: use of generalised linear models. J Health Serv Res Policy 2004;9:197-204. 
32. Rezaei S, Karami Matin B, Hajizadeh M, et al. Economic burden of smoking in iran: a prevalence-based annual cost approach. Asian Pac J Cancer Prev 2017;18:2867-73.

33. Husaini B, Levine R, Lammers $\mathrm{P}$, et al. Smoking, depression, and hospital costs of respiratory cancers: Examining race and sex variation. Fam Med Community Health 2017;5:29-42.

34. Raymakers AJN, Mayo J, Lam S, et al. Cost-Effectiveness Analyses of Lung Cancer Screening Strategies Using Low-Dose Computed Tomography: a systematic review. Appl Health Econ Health Policy 2016:14:409-18.
35. Feirman SP, Glasser AM, Teplitskaya L, et al. Medical costs and quality-adjusted life years associated with smoking: a systematic review. BMC Public Health 2016;16:646.

36. Krueger $\mathrm{H}$, Turner $\mathrm{D}$, Krueger $\mathrm{J}$, et al. The economic benefits of risk factor reduction in Canada: tobacco smoking, excess weight and physical inactivity. Can J Public Health 2014;105:e69-e78.

37. Krueger $\mathrm{H}$, Krueger J, Koot J. Variation across Canada in the economic burden attributable to excess weight, tobacco smoking and physical inactivity. Can J Public Health 2015;106:e171-7. 